\title{
De academische cultuur van artsen
}

Naast de bijdrage van Van Mourik et al. over het kennisniveau van artsen die de verkorte medische opleiding volgen, wil de redactie in dit nummer van het TMO graag aandacht geven aan onderwerpen die te maken hebben met de academische cultuur van artsen. Artsen en artsen in opleiding maken immers deel uit van eenzelfde wetenschappelijke of academische cultuur of gemeenschap. ${ }^{1}$ Net als andere soortgelijke gemeenschappen hebben artsen hun eigen symbolen, betekenissen en overtuigingen. Ook al zijn er verschillen tussen persoonlijkheden, afkomst, gender en nationaliteit, toch zijn er grote gelijkenissen binnen de artsengemeenschap.

Een voorbeeld hiervan is hoe artsen denken over wetenschap. Artsen (met name biomedisch geschoolde artsen en artsen uit de ziekenhuispraktijk) hebben vaak een onbewust idee over wat 'goed wetenschappelijk onderzoek' is maar hebben meestal een tamelijk negatief beeld over sociale wetenschappen. ${ }^{2} \mathrm{Zij}$ verkiezen onbewust - onderzoek met rigoureuze, expliciete standaarden boven onderzoek dat even waardevol kan zijn, maar volgens andere standaarden wordt uitgevoerd zoals bijvoorbeeld etnografisch onderzoek. ${ }^{3}$

Eenzelfde grote onbewustheid leeft bij artsen rond seksespecifieke opvattingen en stereotype beeldvorming; toch kunnen verschillen in gender belangrijk zijn voor de inhoud van de medische zorg. In de bijdrage van Dielissen et al. wordt beschreven hoe in de driejarige Nijmeegse huisartsopleiding een seksespecifiek onderwijsprogramma dat oog heeft voor gender gerelateerde medische zorg, met succes is geïmplementeerd.
Ook beroepen kunnen aanleiding geven tot medische klachten die vragen om een gerichte anamnese. Macfarlane schrijft in zijn bijdrage over het Medisch Centrum voor Dansers en Musici, dat zich naam verworven heeft voor diagnose en behandeling van klachten van mensen uit deze beroepsgroepen.

In 1909 schreef de Franse etnograaf Arnold van Gennep voor het eerst over de Rites de Passage, de overgangsrituelen die in verschillende culturen voorkomen. ${ }^{4}$ Hij beschreef hoe leden van een cultuur via een vastgelegd ritueel de transitie naar een nieuwe identiteit doormaken. Bekende overgangsrituelen zijn de Bar Mitsva, het huwelijk, het debutantenbal...

Ook binnen de geneeskundige academische cultuur zijn overgangsrituelen niet onbekend. Afstuderen en promoveren gaan gepaard met plechtigheden en rituelen, en sinds enige tijd is er ook de Witte Jas Ceremonie (WJC), een ceremonie die plaatsvindt net voordat studenten de medische praktijk ingaan. Dit overgangsritueel is afkomstig uit Amerikaanse medische faculteiten maar is intussen ook overgenomen in andere opleidingen wereldwijd.

Aan het VUmc werd besloten om de WJC in 2008 in te voeren en er een jaarlijkse traditie van te maken. In de bijdrage van Asselbergs-Brüll wordt dit ritueel beschreven. Zoals het een echte rite de passage betreft is er in Amsterdam voor gekozen om met de ceremonie de 'oude' status van de studenten teniet te doen: door de uitreiking van hun bachelordiploma hebben de studenten hun preklinische studie afgerond en kunnen zij een nieuwe specifieke identiteit 
aannemen, die van de medische professional. ${ }^{5}$ Door het ritueel krijgt de student de kans om met een groter bewustzijn mits grondige reflectie - de stap te zetten naar zijn/haar nieuwe rol in de maatschappij, die van coassistent in opleiding, werkzaam in een ziekenhuis of een andere medische praktijk. Het symbool van deze nieuwe status, aangereikt tijdens de opleiding, is in dit geval de witte jas.

In de VS is er naast lof en geldelijke steun vanuit overheidsinstellingen ook kritiek op de WJC. Volgens sommigen zouden de witte jas en de nieuwe identiteit niet veel inhoud hebben en weinig te maken hebben met empathie maar meer met status en paternalisme. Dat dit niet zozeer te maken heeft met de ceremonie van de witte jas zal duidelijk zijn. Het ligt waarschijnlijk eerder aan het hedendaagse gebrek aan duidelijkheid over de identiteit van de arts. Waar de arts vroeger vooral in staat moest zijn om goede medische kennis aan de dag te leggen, moet hij of zij de dag van vandaag kunnen aantonen niet alleen een goede medische expert te zijn, maar ook een geschoolde communicator, een capabele manager en meer. Van artsen wordt immers verwacht dat ze zich aanpassen aan de moderne tijden en mee evolueren.

Consumentenonderzoek heeft echter aangetoond dat het beeld dat de bevolking heeft van artsen weinig veranderd is. Aan Amerikaanse consumenten werd gevraagd naar wat er onmiddellijk in hen opkwam bij het horen van bepaalde woorden, en deze antwoorden werden 'codes' genoemd.
De code die de deelnemers het vaakst toekennen aan een arts is (nog steeds) 'held': artsen roepen associaties op van redding, van gered worden van dreigend gevaar en van het bespaard blijven van een gruwelijk lot. ${ }^{6}$

Het zelfde onderzoek schetst helaas een minder fraai beeld van de omgeving waarbinnen artsen werken, met name het ziekenhuis. De code die daaraan het vaakst werd toegekend was 'fabriek'. Blijkbaar hebben mensen bij een ziekenhuis de onbewuste connotatie van onpersoonlijkheid, van het zijn van een 'product' eerder dan een mens.

\section{Literatuur:}

1 Becher T, Trowler P. Academic Tribes and Territories (2nd Ed.). Buckingham: Open University Press; 2001.

2. Albert M, Laberge S, Hodges BD. Boundary-work in the Health Research Field: Biomedical and Clinician Scientists' Perceptions of Social Science Research. CMAJ 2009;47:171-194.

3. Bloor M. The Ethnography of Health and Medicine. In: Atkinson P. Handbook of Ethnography. London: Sage Publications; 2001.

4. Van Gennep A. Les Rites de Passage (1909). (First published in 1960). Chicago: University of Chicago Press.

5. Huber SJ. The White Coat Ceremony: a contemporary medical ritual. J Med Ethics 2003;29:364366.

6. Rapaille $\mathrm{C}$. The Culture Code: an ingenious way to understand why people around the world buy and live as they do. New York: Broadway Books; 2006.

\section{Griet Peeraer}

